\title{
The value of carbon sequestration and storage in coastal habitat areas in North West of Morocco
}

\author{
Hicham Ait Kacem ${ }^{1,2}$, Mehdi Maanan ${ }^{1}$ and Hassan Rhinane ${ }^{2}$ \\ ${ }^{1}$ Faculty of Sciences Ain Chock, Department of Earth Sciences, University Hassan II, Casablanca, Morocco \\ ${ }^{2}$ National Agency of Land Conservation, of the Cadaster and Cartography, Rabat, Morocco
}

\begin{abstract}
Morocco, like the rest of the world, is experiencing a climate change that threatens a number of wetlands. Marine ecosystems contribute to the regulation of the Earth's climate, but their degradation releases large quantities of greenhouse gases (GHGs) such as carbon dioxide $(\mathrm{CO} 2)$ into the atmosphere. This paper aimed to map and model changes in carbon storage and sequestration for coastal habitats using the INVEST model, using the Sidi Moussa-Oualidia lagoon complex as a case study. To achieve this objective, several data were used, namely, land use and land cover maps between 2003 and 2020, as well as data on the amount of carbon stored in the three basins; biomass, sediment carbon (soil) and dead carbon (litter), and the annual rate of carbon accumulation in biomass and sediment. The results obtained in this work allowed us to compare the two former and current carbon stock and net sequestration scenarios and to evaluate the social cost of carbon in the study area. This study can facilitate the development of a coastal rehabilitation strategy to take advantage of the benefits of these wetlands and, at the same time, to conserve the ecosystem services provided by these environments, including the CBCS
\end{abstract}

\section{Introduction}

The ecosystem service of carbon sequestration and storage, linked to the provision of an equitable climate, is research subject in full progress. In this context, the carbon storage potential of coastal habitats plays an important role in regulating local and global climate [1-2]. However, in recent years coastal habitats are under threat and are deteriorating all over the world. The main drivers of this decline are urban and industrial development, agriculture, aquaculture, tourism, coastal erosion and sea level rise. This ecosystem service in coastal systems is of social and economic importance, although it is poorly represented in events and decisions related to global climate change. Studies in this direction remain isolated and limited in some parts of the world. In addition, there is a continuing need for in situ data at national and local scales. This study is was conducted in the lagoon complex of Sidi Moussa-Oualidia located in Atlantic coast of Morocco. The objective of this study was to assess the monetary value of the coastal blue carbon sequestration service provided by coastal ecosystems by analysing changes in carbon storage and based on changes in LULC over the period between 2003 and 2020.

We used the InVEST CBC model to: (1) Establish a detailed mapping of coastal ecosystems over time, (2) Monitor the evolution of carbon stocks over the last 17 years, (3) Quantify carbon sequestration in relation to land use change and climate change, and (4) Estimate the economic value of the CBCS provided by coastal ecosystems [3].
In this paper and using the latest estimates of the social cost of carbon, we estimated the economic value of the gain and loss of

Blue carbon by coastal ecosystems across the Sidi Moussa-Oualidia lagoon complex.

\section{Study area}

The Sidi Moussa-Oualidia lagoon complex is located in the Casablanca-Settat region on the Atlantic coast of Morocco. Its geographical coordinates are $32^{\circ} 52^{\prime} 0^{\prime \prime} \mathrm{N}$ latitude and $8^{\circ} 51^{\prime} 05^{\prime \prime}$ W longitude (Figure 1).

The total surface area is estimated at $95 \mathrm{Km}^{2}$. There are three zones (permanent passes and internal tidal delta, channels (5m maximum depth), intertidal zones and schorres invaded by halophyte vegetation and salt marshes at the bottom of the water mass, separated. This lagoon has the peculiarity of being separated from the oceanic zone by a consolidated dune barrier, which ensures the stability of the lagoon-ocean communication. Due to the southern latitude, the average annual rainfall remains low and hardly exceeds $361 \mathrm{~mm}$, which places it in a semi-arid climate. The difference recorded between the driest and wettest months can reach up to 66 $\mathrm{mm}$. The rainfall frequency curve, (oualidia climate table, Data-Climat 2020), shows a rainy season extending from autumn (October) to spring. The drought starts in June and continues until September. During this period, rainfall is exceptional. The average annual temperature (average monthly mean temperature) is around $18.3^{\circ} \mathrm{C}$. 


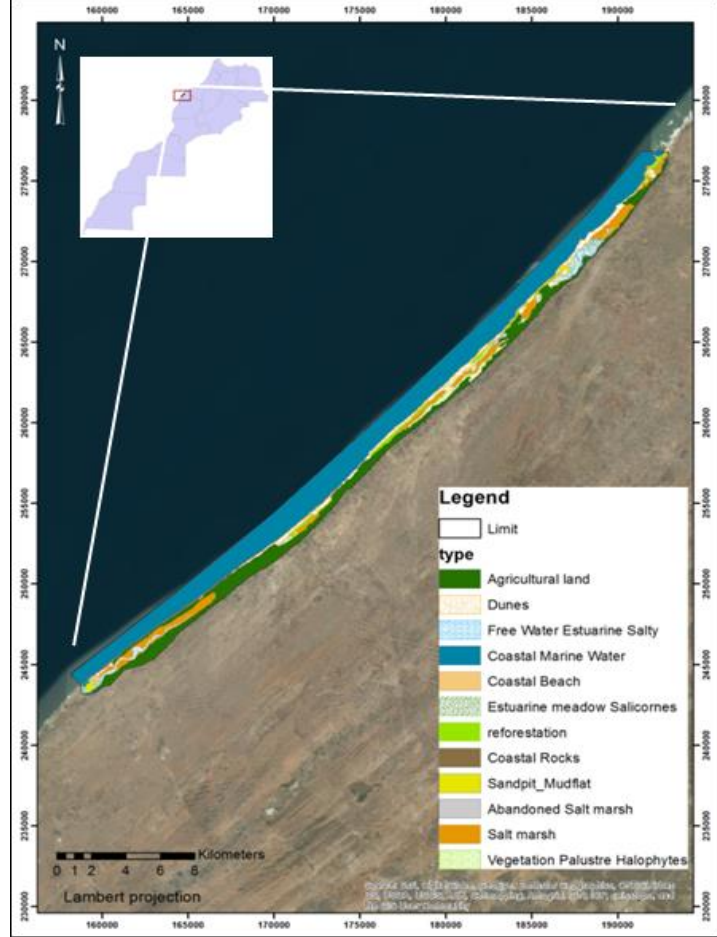

Fig. 1. Location of the study area.

The lagoon complex of Sidi Moussa-Oualidia belongs to the large morphological unit of the Sahel Doukkala, corresponding to a coastline that extends over $150 \mathrm{~km}$ in an SSW-NNE orientation, parallel to the shoreline, between the towns of Azemmour and Safi. The subsoil of this unit is essentially made up of consolidated tertiary or quaternary marine sands, surmounting a cretaceous base.

The region is poor in soils, the richest being limited to the interdunary depressions, where market gardening abounds. Five types have been inventoried in the region: Hamri, sandy soil or sandy loam, deposited on a limestone crust at the level of depressions; Hrach, soil that is easy to work; Shots, deep black soil, rich in humus and compacts; and saline hydromorphic soils, with a clay texture, are found in the merjas and lagoons [4].

\section{Methods and Data used}

\subsection{Methods}

On the basis of a dozen othophotos with a resolution of one meter, obtained from the National Agency of Land Conservation of the Cadastre and Cartography (ANCFCC), a detailed cartography of the lagoon complex of Sidi Moussa-Oualidia was established during the two periods (Figure 3). The LULC has been classified into twelve major types. To analyse the changes in LULC between 2003 and 2020, we used ArcGIS software for data processing and chord diagram software for the visualisation of different LULC transformations. In addition, to calculate the amount of the blue carbon sequestration service provided by coastal ecosystems based on changes in LULC and to estimate the economic value of this CBCS service, the InVEST model was used (Figure 2). InVEST Coastal Blue Carbon models the carbon cycle using an accounting approach [5]. This approach simplifies the carbon cycle by accounting for storage in three main basins: biomass, sediment carbon (i.e. soil) and dead carbon (i.e. waste). Carbon accumulation in coastal habitats occurs mainly in sediments (Pendleton et al, 2012). The InVEST CBC model requires maps of coastal ecosystems in addition to biophysical data of carbon stored in the three basins and the annual rate of carbon accumulation in biomass and sediments. The economic data are required to model the monetary value of carbon sequestration [3]. The input data for the study site of the lagoon complex of Sidi Moussa-Oualidia were acquired using local values from recent blue carbon research and from the Intergovernmental Panel on Climate Change's (IPCC) database (Table 1).

\subsection{Data used}

To map LULC classes to their values in a raster, as well as to indicate whether or not the LULC class is a blue-carbon coastal habitat. We created a LULC lookup table (CSV). Then we defined input parameters for carbon data consisting of carbon pool storage and accumulation rates, soil and biomass disturbance magnitude, and carbon decay rates (Figure 2).

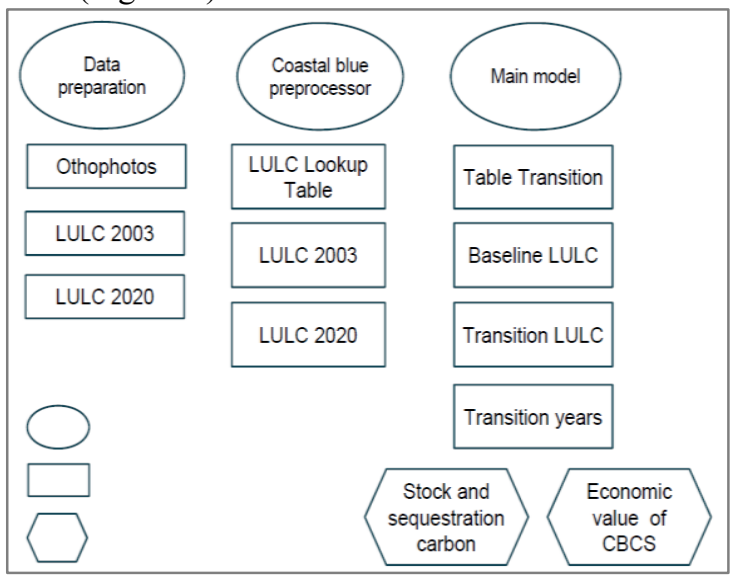

Fig. 2. Hierarchical structure of coastal blue carbon.

\subsubsection{Biophysical data}

\subsubsection{Carbon stock in the soil}

The soil organic carbon stock (SCOS) in the five coastal blue carbon habitats for a depth (up to 30 $\mathrm{cm})$ varies from $85 \mathrm{MgC}^{-h^{-1}}$ to $110 \mathrm{MgC}^{-h^{-1}}{ }^{\text {, }}$ respectively, for Vegetation Palustre Halophytes and Cultivated land (Table 1). 


\subsubsection{Carbon stock in biomass}

The carbon stock of the above-ground and belowground biomass varies from $7.3 \mathrm{MgC}^{-\mathrm{ha}^{-1}}$ to 41 $\mathrm{MgC} \mathrm{ha}^{-1}$, respectively, for cultivated land and shrub and forest (Table 1).

\subsubsection{Organic carbon stock in litter}

Compared with the biomass and soil carbon stock, organic carbon stock values in soil litter remain very low.

\subsubsection{Carbon accumulation}

Accumulation is defined as the amount of carbon retained in soil in an organic form after the first year of decomposition. This accumulation participates in the development of "reservoirs" of carbon, which are considered permanent, if not undisturbed. Thus, even without a change in land use or land cover, carbon continues to be sequestered naturally. All LULC classes of noncoastal blue carbon habitat are assumed not to sequester or emit carbon as a result of the change. "Annual accumulation" values are expressed in tonne of $\mathrm{CO}_{2}$ eq/ha-yr. "Half-life" values are expressed in years. "Disturbance" values are expressed as a decimal percentage of the disturbed stock.

\subsubsection{Carbon emissions}

When coastal ecosystems are degraded by human activities, carbon stored in living plant material (above and below ground) and in the soil can be released into the atmosphere. The extent of $\mathrm{CO}_{2}$ release after conversion depends on the type of vegetation disturbed and the level of disturbance. The type of disturbance will determine the amount of aerial biomass loss and the depth at which the soil profile will be modified. The deeper the effects of disturbance are, the more soil carbon that will be exposed to oxygen, oxidized and therefore emitted as $\mathrm{CO}_{2}$. Some disturbances will disturb only the upper layers of the soil while the deeper layers will remain flooded and their carbon intact. Other disturbances can affect several meters of the soil profile. To estimate the magnitude of the impact of various disturbances, we classify disturbances into three impact categories: high, medium and low. If the cell is empty, no such transition occurs between snapshots. For no change of carbon the cell is named "NCC". The leftmost column represents the source LULC class and the top line represents the destination LULC class (Table 2).

\subsubsection{Economic data}

To encourage economic decision-makers to invest more in clean energy or low-carbon technologies and less in GHG-emitting technologies, some States have decided to give an economic value to the emission of one tonne of $\mathrm{CO}_{2}$. The social cost of carbon (SCC) refers to the economic damage avoided by removing one metric tonne of $\mathrm{CO}_{2}$ (or $\mathrm{CO}_{2}$ equivalent) from the atmosphere. Taking into account the daily carbon market prices over the year 2020 according to the European Emission Allowances $/ \mathrm{tCO}_{2}$ eq:

(www.markets.businessinsider.com/commodities/co2european-emission-allowances, 2020). The financial value of carbon stocks has been estimated at $(€ 25)$.



Fig. 3. Land use evolution in lagoon complex of Sidi Moussa-Oualidia.

Table 1. Values of carbon pools.

\begin{tabular}{|c|c|c|c|c|c|}
\hline $\begin{array}{l}\mathbf{N} \\
\mathrm{o}\end{array}$ & LULC types & $\begin{array}{c}\text { (AGB \& BGB) } \\
\text { (Mg ha-1) }\end{array}$ & $\begin{array}{c}\text { LB } \\
\text { (Mg } \\
\text { ha-1) }\end{array}$ & $\begin{array}{c}\text { SOC } \\
\text { (Mg } \\
\text { ha-1) }\end{array}$ & $\begin{array}{c}\text { Reference } \\
\mathrm{s}\end{array}$ \\
\hline 1 & Cultivated land & 7,3 & 1 & 110 & IPCC \\
\hline 2 & $\begin{array}{l}\text { Estuarine Meadow } \\
\text { Salicorne }\end{array}$ & $15,3^{(a)}$ & 1 & $97,5^{(\text {b) }}$ & $\begin{array}{l}\text { (a) }[6] \\
\text { (b) }[7]\end{array}$ \\
\hline 3 & Shrub and Forest & 41 & 1 & 88 & IPCC \\
\hline 4 & mudflat and sandpit & - & 0 & 143 & [8] \\
\hline 5 & $\begin{array}{l}\text { Vegetation Palustre } \\
\text { Halophytes }\end{array}$ & 8,66 & 1 & 85 & [9] \\
\hline
\end{tabular}

\section{Results and discussion}

In 2003, the main coastal habitats identified in the study area were agricultural land $(42.58 \%)$, salt pans $(18.65 \%)$, coastal dunes $(12.39 \%)$, shrub and forest $(4.92 \%)$ and vegetation palustre halophytes (4.79\%) (Figure 4).

Agricultural areas were mainly used for market gardening followed by oyster farms. The chord diagram shows that land use has undergone short changes since 2003. For the period (2003-2020), agricultural land remained relatively stable $42.46 \%$ to $42.58 \%$ same for salt pans $18.68 \%$ to $18.65 \%$, the areas occupied by coastal dunes are increased from $10.73 \%$ to $12.39 \%$. However, there is a reduction in the area of shrub and forest from $6.65 \%$ to $4.79 \%$ in the coastal margin in favor of coastal dunes, this decrease is mainly due to the rise in sea level and the expansion of beach sands. Note through the results of this study, that was carried out on an area of about 3292 hectares of coastal dwellings of the complex Sidi Moussa Oualidia (Figure 5), that the amount of carbon stock in 2003 reached a total of $143 \mathrm{~T} / \mathrm{ha}$ (tons/hectare) which represents 0.47 Mt.C (Megatonnes) for the total surface studied. 


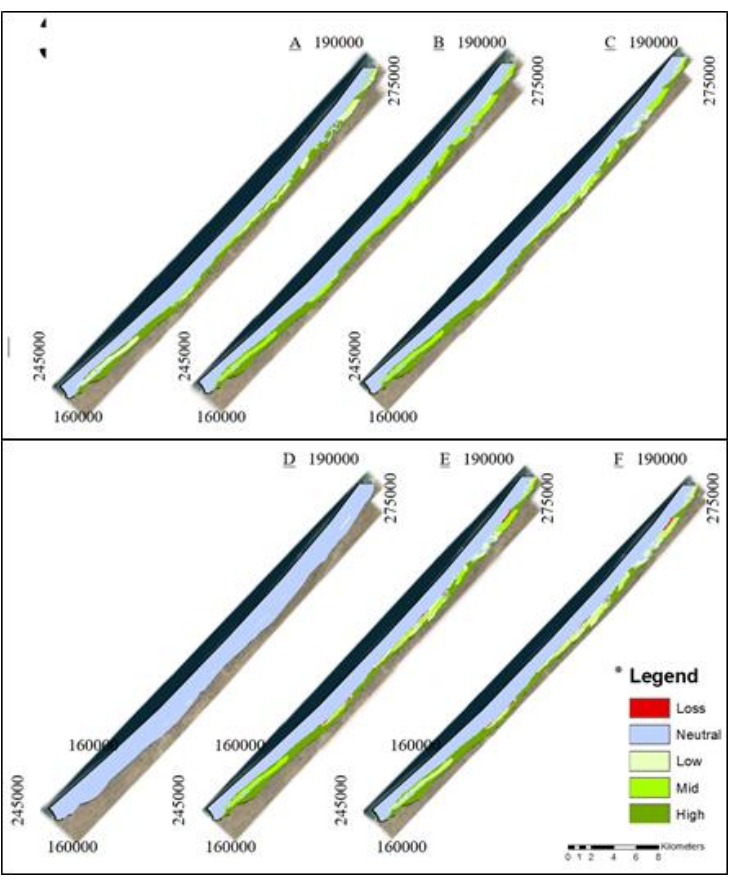

Fig. 5. (A) Carbon stock in 2003, (B) Carbon stock in 2020, (C) Carbon accumulation between 2003 and 2020, (D) Carbon emissions between 2003 and 2020, (E) Carbon sequestration between 2003 and 2020, (F) Total net carbon sequestration. (* The legend designates results in a qualitative way).

In the year 2020, this quantity reached a value of 471T/ha which means 1.55 Mt.C of total area. This increase is due in particular to the development of the cultivated area. In addition, in the absence of a change in land use or land cover, carbon continues to be accumulated naturally to record 327T/ha which is equivalent to $1.08 \mathrm{Mt}$.C at the Sidi Moussa Oualidia lagoon.

For carbon emissions during the same period, the value is set at $-85 \mathrm{~T} /$ ha $(-0.28 \mathrm{Mt}$.C of total area), released mainly by the degradation of reforestation that has been damaged by the expansion of sand dunes.

For total net carbon sequestration, it is estimated at $242 \mathrm{~T} /$ ha which represents $0.80 \mathrm{Mt}$.C for the study area. For the revenues from the storage of coastal blue carbon during the period (2003-2020) we estimate the equivalent value of gain in Euro at the prices to the European Emission Allowances $/ \mathrm{tCO}_{2}$ eq at $€ 19,916,600$.

\section{Conclusion}

This study examined how the quantity and value of carbon sequestration service in coastal habitats is changing over time. It has shown that coastal habitats have a significant value in terms of stored and sequestered $\mathrm{CO}_{2}$.
These Coastal Ecosystems have the potential to increase if the current area of coastal habitat is developed. The sequestration capacity during the period between 2003 and 2020 is estimated at approximately $242 \mathrm{~T} / \mathrm{ha}$. However, if sea level rises and coastal erosion continues to increase, or if land conversion tends to lose more habitats, the ability of coastal habitats to store and sequester $\mathrm{CO}_{2}$ will be significantly reduced. Finally, it should be noted that carbon sequestration and storage are just one of the many ecosystem services provided by coastal habitats.

Other services provided by coastal habitats include coastal defense, recreation, nutrient and contaminant storage and recycling, and fish nursery areas. The financial returns from carbon storage and sequestration presented here provide a compelling argument for maintaining these habitats, through awareness of the need to conserve these marginal coastal habitats in order to maintain ecosystem services.

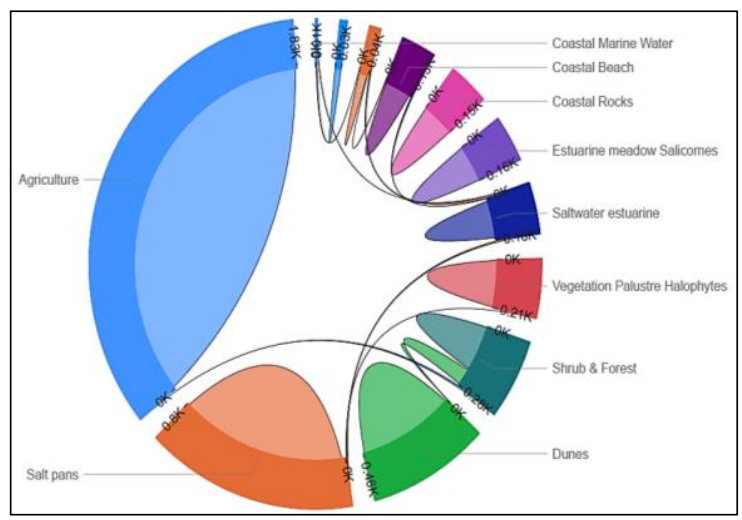

Fig. 4. Areal of LULC changes between 2003 and 2020

Table 2: Transition table

LULC-class

Mudflat and sandpit

Shrub and Forest

Estuarine Meadow Salicorn Coastal Beach

Coastal Marine Water

Free Water Estuanine Salty Vegetation Palustre Halophytes Coastal dunes

Actives Salines

Cultivated land Abandoned Salines Coastal Rocks

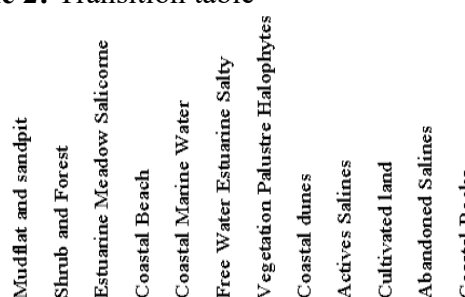

High disturbance $\quad$ No transition

\begin{tabular}{l|l} 
Medium disturbance & Accumulation \\
\hline
\end{tabular} 


\section{Acknowledgement}

The authors gratefully acknowledge the contributions of all reviewers for their scientific suggestions and constructive comments. We thank Mehdi Maanan and Hassan Rhinane for the supervision during the preparation of this manuscript. We also acknowledge the support of the National Agency of Land Conservation of the Cadastre and Cartography (ANCFCC).

\section{References}

1. A.E. Sutton-Grier and P.A. Sandifer, Wetlands, 39, 1295-1302 (2019)

2. 2. W.J. Mitsch, B. Bernal, and M.E. Hernandez, Int. J. Biodivers. Sci. Ecosyst. Serv. Manag, 11, 1-4 (2015)

3. H.T. et R.T. et G.A.D. et W.S.A. et C.-K.R. et N.E. et E.D. et W.S. et O.N. et autres Sharp R et Tallis, N, "InVEST +VERSION+ User's Guide. (2014)

4. R. El Hamoumi, M. Dakki, H. Rguibi Idrissi, and M. Radi, "Fiche descriptive sur les zones humides Ramsar (FDR) : Complexe de Sidi Moussa-Walidia (Maroc), 10 (2003)

5. R.A. Houghton, Tellus, Ser. B Chem. Phys. Meteorol, 55, 378-390 (2003)

6. D. Laffoley and G. Grimsditch, the Management of Natural Coastal Carbon Sinks, no. (November 2009)

7. L.M. Schile, J.B. Kauffman, S. Crooks, J.W. Fourqurean, J. Glavan, and J. P. Megonigal, Ecol. Appl, 27, 859-874 (2017)

8. V.X.H. Phang, L.M. Chou, and D.A. Friess, Earth Surf. Process. Landforms, 40, 13871400, (2015)

9. G. Curado, A.E. Rubio-Casal, E. Figueroa, B.J. Grewell, and J.M. Castillo, Environ. Monit. Assess, 185, 8439-8449 (2013)

10. Www.markets.businessinsider.com/commoditi es/co2-european-emission-allowances, "CO2 European Emission Allowances." www.markets.\%0Abusinessinsider.com/comm odities/co2-european-emission-allowances. 